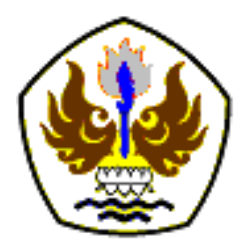

INFOMATEK

Volume 21 Nomor 2 Desember 2019

\title{
PERANCANGAN SISTEM INFORMASI MANAJEMEN KEGIATAN PEGAWAI PADA KANTOR URUSAN AGAMA (KUA)
}

\author{
Rizal Fadila*), Ferry Ferdian Djaelani \\ Program Studi Sistem Informasi \\ Universitas Komputer Indonesia
}

\begin{abstract}
Abstrak: Di tengah perkembangan zaman saat ini, teknologi berperan sangat penting dalam bidang kehidupan, hal ini disebabkan karena teknologi memberikan banyak kemudahan seseorang dalam menyelesaikan pekerjaan. Salah satunya yaitu di bidang perkantoran, seiring dengan hadirnya teknologi komputer di bidang perkantoran maka proses dan pengolahan data menjadi cepat, tepat dan akurat. KUA merupakan salah satu instansi pemerintah yang bergerak di bidang keagamaan, baik dalam hal pelayanan pernikahan, pelayanan wakaf, pelayanan haji, pelayanan pendaftaran talak atau rujuk, serta berbagai layanan dalam bidang keagamaan yang lainnya. Berdasarkan penelitian yang kami buat saat ini sistem pengolah data kegiatan pegawai telah menggunakan komputer namun hanya bisa mengolah beberapa kegiatan pegawai saja, seperti pelayanan pernikahan dan pelayanan wakaf, sedangkan dalam pembuatan laporan kegiatan sehari-hari belum melibatkan penggunaan teknologi komputer sehingga dalam pencatatan laporan menjadi tidak sama seperti keadaan di lingkungan kerja. Aplikasi Sistem Informasi Manajemen Kegiatan Pegawai ini dirancang untuk menyelesaikan permasalahan yang ada sehingga diharapkan bisa mengolah data semua kegiatan dan membuat laporan secara efisien sehingga diharapkan dapat mengurangi potensi kesalahan dalam pengolahan data.
\end{abstract}

Kata kunci: Sistem Informasi, Sistem Informasi Manajemen, Pegawai, KUA

\section{PENDAHULUAN}

Seiring dengan perkembangan ilmu pengetahuan dan teknologi (IPTEK), teknologi memegang peranan penting dalam berbagai bidang. Hal ini disebabkan karena teknologi memberikan banyak kemudahan bagi seseorang dalam menyelesaikan pekerjaan. Salah satunya di bidang perkantoran, pengunaan teknologi

*) rizalfadila52@gmail.com

Pertama diterima : 22 Juli 2019

Direvisi : 7 Agustus 2019

Disetujui untuk publikasi: 18 Agustus 2019 khususnya teknologi komputer sangat dibutuhkan untuk mengolah data menjadi cepat, tepat dan akurat agar perkerjaan kantor menjadi lebih efektif dan efisien serta informasi yang dihasilkan juga lebih akurat, tepat waktu dan relevan (Choirunsyah dkk., [1]). Sehingga dalam hal ini akan memudahkan manager untuk mengambil keputusan.

Kantor Urusan Agama (KUA) adalah Unit Pelaksana Teknis Direktorat Jendral 
Bimbingan Masyarakat Islam yang bertugas melaksanakan sebagian tugas kantor Kementrian Agama Kabupaten atau Kota di bidang urusan agama Islam (Jimsan dkk. [2]). Beberapa tugas yang dilaksanakan KUA adalah pelayanan pernikahan, keuangan, wakaf, bimbingan manasik haji, serta berbagai tugas lain di bidang agama Islam. Dalam melaksanakan beberapa tugas tersebut KUA diperintahkan menyusun Sasaran Kerja Pegawai (SKP) untuk penilaian prestasi kerja. Penilaian prestasi kerja dilaksanakan oleh Pejabat Penilai sekali dalam 1 (satu) tahun. Sedangkan untuk merealisasikan SKP tersebut Pegawai Negeri Sipil (PNS) diwajibkan membuat Laporan Capaian Kinerja Harian (LCKH) yang nantinya digunakan sebagai pencairan tunjangan kinerja (TUKIN). Dengan demikian dalam pembuatan laporan membutuhkan data yang akurat agar penilaian prestasi kerja menjadi lebih efektif.

Di KUA dalam mengolah kegiatan pegawai sudah menggunakan sistem yang terkomputerisasi namun sistem tersebut hanya mengolah data pelayanan pernikahan, wakaf dan kemasjidan (Yanto dkk. [3]) (Farida dkk. [4]), (Nurhakim dkk. [5]) Sistem tersebut sudah distandarisasi secara nasional oleh Kementerian Agama. Sedangkan dalam pembuatan laporan SKP dan LCKH masih dengan cara manual sehingga sering terjadi ketidakcocokan data antar pegawai. Tentu saja ini membuat penilaian prestasi kerja menjadi kurang efektif dan akan berimplikasi negatif terkait dengan pencairan TUKIN.

Melihat dari berbagai permasalahan tersebut pihak KUA merasa membutuhkan sistem yang bisa mengolah data semua kegiatan dan juga menghasilkan laporan SKP dan LCKH secara detail, akurat dan efisien. Hal tersebut menjadi latar belakang untuk merancang Sistem Informasi Manajemen Kegiatan Pegawai berbasis dekstop yang bisa menyelesaikan berbagai permasalahan di KUA.

\section{METODOLOGI}

Dalam penelitian ini menggunakan metode System Development Life Cycle (SDLC) untuk membuat program dan mengembangkannya sesuai dengan apa yang diharapkan. Metodologi penelitian disusun dalam rangka untuk memudahkan proses analisis dan perancangan desain aplikasi dan dibagi ke dalam beberapa tahapan. Tahapan-tahapan tersebut, antara lain:

1. Pengumpulan Data

Dalam mengumpulkan informasi tentang bagaimana proses-proses pada sistem lama yang berjalan dan menentukan bagian mana saja proses yang bisa selesaikan dengan sistem informasi, 
maka Penulis melakukan beberapa cara seperti berikut:
a. Observasi / Survery
Metode ini dilakukan dengan cara mengamati kegiatan di KUA.
b. Wawancara
Metode wawancara adalah metode penelitian yang dilakukan dengan cara melakukan wawancara secara langsung kepada pihak KUA Kec. Klaten Selatan untuk mendapatkan informasi yang akurat tentang masalah yang ada.

\section{Perancangan}

Perancangan adalah proses mengubah kebutuhan yang masih berupa konsep menjadi spesifikasi sistem yang nyata. Proses perancangan dibagi dalam 2 tahapan, antara lain:
a. Perancangan Logis
Pada proses perancangan logis digunakan untuk membuat beberapa dokumen, diantaranya model data, model proses, rancangan tabel, dan perancangan antar muka dari sistem yang akan dibuat.
b. Perancangaan Fisik
Pada bagian ini digunakan untuk mengubah spesifikasi logis ke dalam detail teknologi di mana pemrograman dan pengembangan sistem bisa diselesaikan. Pada

proses inilah kegiatan pengkodean (coding) dilakukan

3. Implementasi

a. Testing

Testing dilakukan untuk menguji hasil kode program yang dihasilkan dari perancangan fisik. Dalam pengujian ini ada 2 tujuan, antara lain:

- Dari sisi pengembang

Kode program harus dijamin tidak ada kesalahan sintaks maupun logika.

- Dari sisi pengguna

Sistem yang dihasilkan harus bisa menyelesaikan masalah yang ada di KUA Kec. Klaten Selatan dan sistem harus user frendly.

c. Instalasi

Pada tahap ini setelah system lolos testing, maka software dan hardware akan diinstal di KUA.

4. Pemeliharaan

Pada proses ini sistem secara sistematis diperbaiki dan ditingkatkan. Proses ini digunakan untuk pembaruan versi dari software yang telah dibuat. Beberapa perbaikan dilakukan seperti memperbaiki program yang error dan penambahan fitur-fitur baru untuk memenuhi kebutuhan pengguna. 
III. ANALISIS DAN PEMBAHASAN

\subsection{Analisis Sistem Berjalan}

Gambar 1 adalah hasil dari analisis yang telah dilakukan pada KUA yang sudah ada.

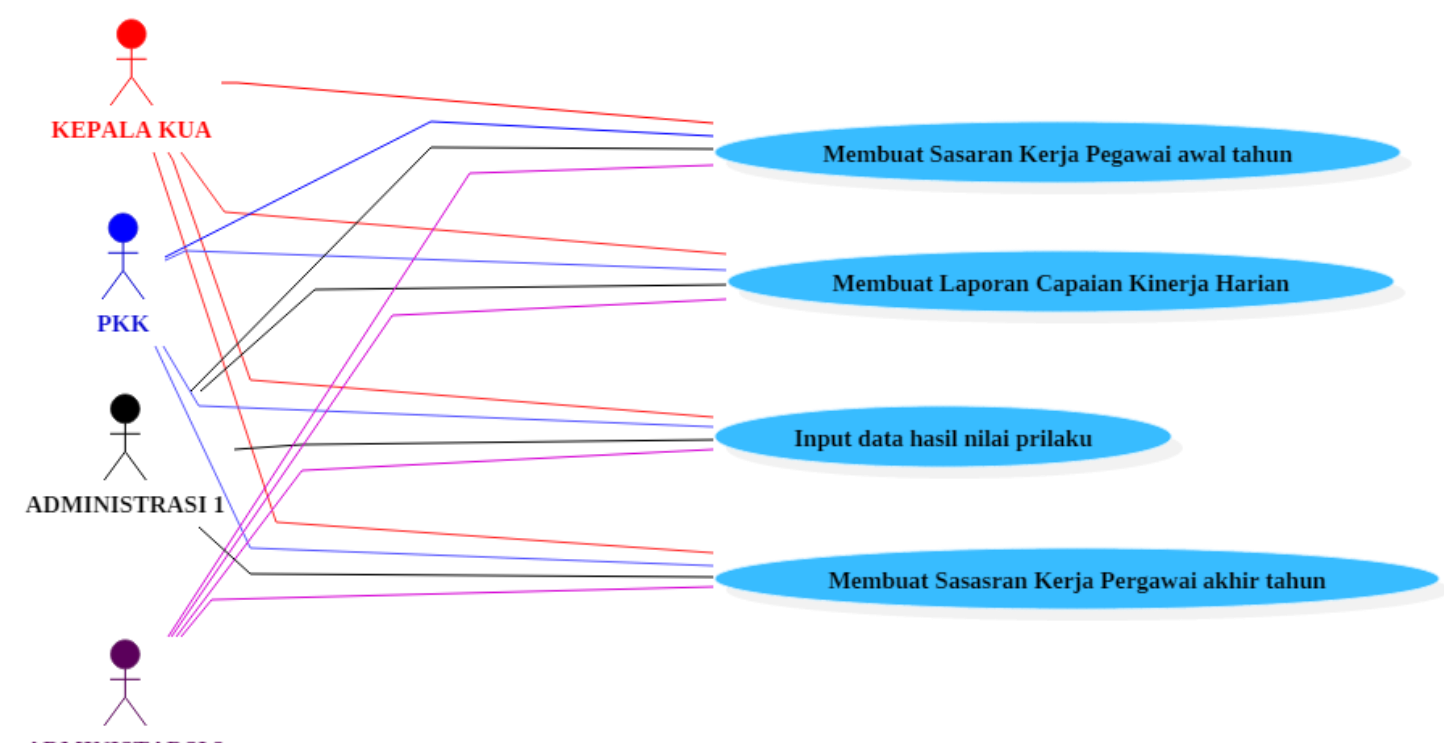

Gambar 1.

Diagram Use Case system yang berjalan di KUA

\subsection{Perancangan Sistem}

Dalam merancang sistem yang akan digunakan di Sistem Informasi Manajemen Kegiatan Pegawai, peneliti menggunakan model perancangan UML (Unifed Modeling Language). UML dipilih karena dalam merancang sistem peneliti menggunakan pemrograman berorientasi objek atau yang sering disebut dengan OOP (Object Oriented Programming).

a. Use Case Diagram

Gambar 2 adalah use case diagram yang ditujukan guna menunjukkan interaksi antara pengguna dan entitas eksternal lainnya dengan sistem yang sedang dikembangkan.
Use case diagram yang diusulkan yaitu bahwa pengelolaan di server meliputi panel control, data pegawai, data atasan penilai, data jenis kegiatan, data kegiatan, data kegiatan pegawai, data logi pegawai, data penilai, data unit kerja, dan data administrator. Sedangkan pada bagian Klien, pengelolaan yang dapat dilakukan adalah data sasaran kerja, data capaian kinerja harian, data login pegawai, data realisasi, data ukur sasaran kerja, data perilaku kerja, serta cetak laporan.

Masing-masing pengelolaan memiliki beberapa opsi seperti tambah, hapus, cari, dan lihat, sesuai dengan kewenangan dan tugas. 


\section{b. Class Diagram}

Diagram kelas atau class diagram menggambarkan struktur sistem dari segi pendefinisian kelas-kelas yang akan dibuat untuk membangun sistem (Suendri [6]). Gambar 3 memperlihatkan Class Diagram yang diusulkan.

Class diagram yang diusulkan seperti Gambar 3 memperlihatkan hubungan antar class yang berfokus pada peran pegawai.
Setiap peran pegawai yang masuk dengan login terhubung dengan data pribadi, unit kerja, perilaku kerja, kegiatan, jenis kegiatan, detail kegiatan dan capaian kegiatan harian. Capaian kegiatan dinilai dengan sasaran kerja, realisasi kerja dan ukur sasaran.

Penilaian dilakukan oleh atasan penilai dan pejabat penilai yang mempertimbangkan perilaku kerja dan sasaran kerja.

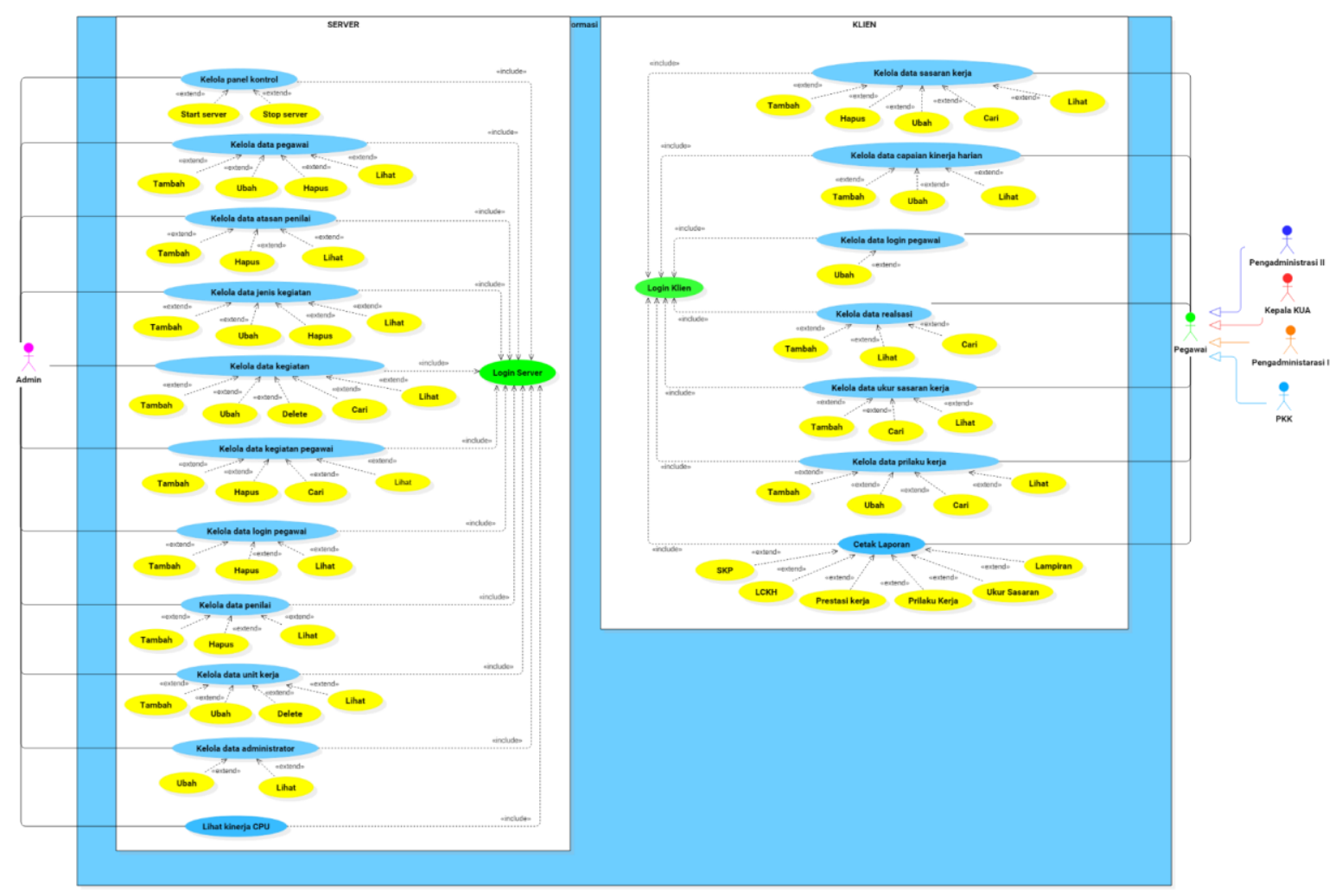

Gambar 2.

Use Case Diagram yang diusulkan 


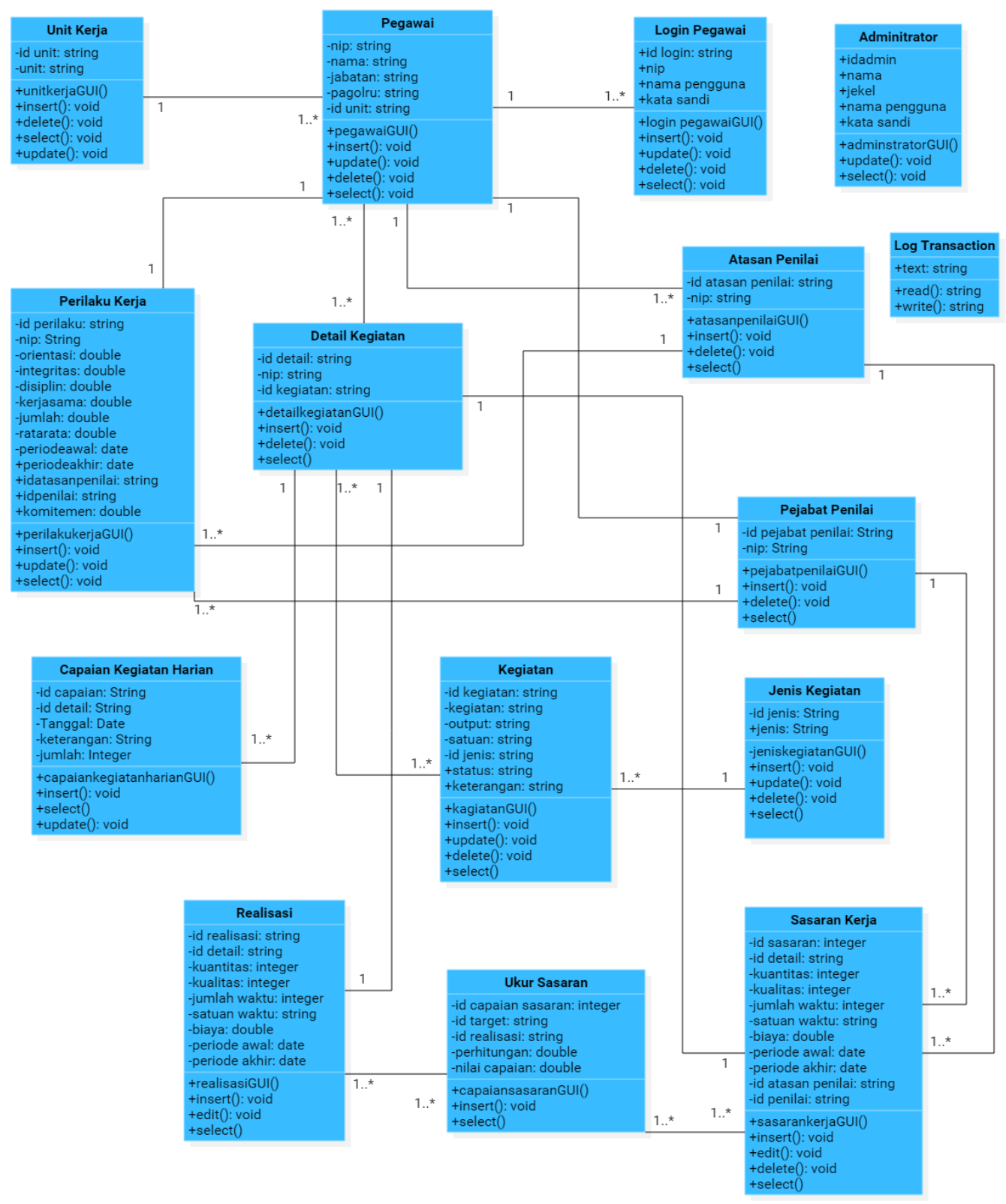

Gambar 3.

Class Diagram yang diusulkan 


\section{KESIMPULAN}

Pelayanan dan penyajian informasi yang cepat, tepat dan akurat sangat penting sekali bagi suatu instansi maupun lembaga. Seiring dengan perkembangan ilmu pengetahuan dan teknologi yaitu adanya sistem pengolahan data menggunakan komputer (basis data) berperan penting dalam pembuatan laporan yang cepat, tepat dan akurat.

Berdasarkan penelitian yang dilakukan dengan metode wawancara, mengamati dan menganalisa permasalahan sinkronisasi data serta dilandasi oleh teori-teori maka perlu diterapkan dan digunakan sebuah sistem komputer dengan menggunakan suatu paket aplikasi. Dengan sistem tersebut dapat menggantikan sistem lama yang selama ini menggunakan Microsoft Excel.

Kesimpulan dari kajian ini adalah:

1. Aplikasi ini mampu mengatasi semua permasalahan di KUA.

2. Sistem ini juga mampu mengelola data pegawai, data kegiatan, data pagolru, data atasan penilai, dan lain sebagainya yang dibutuhkan dalam penyusunan laporan.

3. Adanya sistem ini bisa mengatasi keterlambatan laporan.

\section{DAFTAR PUSTAKA}

[1] Choirunsyah, F.A., Heryanto, H. "Perancangan Knowledge Management System pada Tenaga Kependidikan di Perguruan Tinggi," Infomatek, Jurnal Informatika, Manajemen dan Teknologi, vol 21 no. 1, pp.1-14, 2019.

[2] Jimsan, Qomaruddin, M., Mustafa. "Sistem Informasih Manajemen Data Pernikahan pada Kantor Urusan Agama (KUA) Bonegunu," Jurnal Transistor Elektro dan Informatika, vol. 2 no. 1, pp. 57-67, 2017.

[3] Yanto, I., Noviyanto, F. "Pengembangan Sistem Layanan Kantor Urusan Agama," Jurnal Sarjana Teknik Informatika, vol. 3 no. 3, 2015.

[4] Farida, S., Bunyamin. "Pengembangan Aplikasi Pencatatan Nikah di Kantor Urusan Agama Kecamatan Cikajang Garut," Jurnal Algoritma, vol. 12 no. 1, pp. $1-7,2015$

[5] Nurhakim, L., Umar, R. "Sistem Informasi Pernikahan pada Kantor Urusan Agama (KUA) di Kecamatan Banjarharjo Kabupaten Brebes," Jurnal Sarjana Teknik Informatika, vol. 3 no. 1, pp. 39-48, 2015.

[6] Suendri. "Implementasi Diagram UML (Unified Modelling Language) pada Perancangan Sistem Informasi 
Infomatek Volume 21 Nomor 2 Desember 2019 : 69 -76

Remunderasi Dosen dengan Database

Oracle (Studi Kasus: UIN Sumatera Utara

Medan)," Algoritma, Jurnal IImu Komputer

dan Informatika, vol. 3 no. 1, pp. 1-9, 2018. 